\footnotetext{
1,2. Universidad Pedagógica y Tecnológica de Colombia, Colombia karen.chacon01@uptc.edu.co

Como citar: Chacón Quiroga, K., \& Duarte Báez, L. (2020). Experiencias Filosóficas con la Primera Infancia: Entrevista a Walter Kohan. EDUCACIÓN Y CIENCIA, (24), e12281. https://doi. org/10.19053/0120-7105.eyc.2020.24. e12281
}

\section{Experiencias Fillosóficas con la Primera Infancia:
trevista a Walter Kohan con la Primera Infancia:
Entrevista a Walter Kohan}

Por:

Karen Julieth Chacón Quiroga ${ }^{1}$

Leidy Yulieth Duarte Báez ${ }^{2}$

El doctor Walter Kohan estudió filosofía en la Universidad de Buenos Aires, se doctoró en esta misma área en la Universidad Iberoamericana de México, y entre los años 2005 y 2007, realizó estudios de Posdoctorado en la Universidad de Paris VIII (Université de Vincennes à Saint-Denis). Sus principales áreas de interés son la enseñanza de la filosofía, las relaciones entre filosofía e infancia, la filosofía antigua, y la filosofía de la educación. Actualmente, es docente en la Universidad del Estado de Río de Janeiro donde participa y coordina numerosos proyectos interinstitucionales de investigación y formación del profesorado.

Así mismo, ha desarrollado un importante trabajo con el programa "Filosofía para Niños", el cual, inicialmente trabajó en Argentina y luego lo llevó a Brasil, hace ya más de diez años. Entre 1999 y 2001 fungió como presidente del Consejo Internacional de Investigación Filosófica con Niños (ICPIC por sus siglas en inglés). Su producción académica entre libros, capítulos de libro, artículos, editor y coeditor, es extensa y representa una fuente de referencia para el ámbito filosófico, donde su relación y abordaje de la infancia, la filosofía y la educación, invitan a pensar de otro modo, a vivir desde la libertad, así, desde el tiempo aiónico, a valorar la pregunta como un horizonte de saber, no en el sentido de adquirir una respuesta o caminos definitorios, sino para entender y animar los múltiples lenguajes de la infancia.

Recibido: $27 / 08 / 2020$ | Revisado: 25/09/2020

Aprobado: 30/10/2020 | Publicado: 30/12/2020 
L. D. Quisiéramos iniciar hablando sobre ¿quién es Walter Kohan?

Walter Kohan. (W. K.) Creo que una de las cosas que podría decir de quien soy es que soy un niño, que por suerte, trato de cuidar mi infancia, trato de no olvidarla, de recuperarla y estar atento a ella. Entonces soy como una especie de niño que juega a ser adulto, un adulto que juega a ser un niño y que encontró en la filosofía un juguete maravilloso para recordar qué es un niño.

K. CH. - ¿Cuándo y cómo inició su interés hacia la filosofía para y con niños?

W. K. Yo trabajaba en la Universidad de Buenos Aires como profesor de filosofía antigua, un día vi una convocatoria para interesados en el programa de filosofía para niños, en ese momento yo no había escuchado hablar del tema, entonces, decidí asistir, eso pasó hace más de 30 años. Debo decir, que me gustó mucho la manera en que la filosofía se vivía, no como un saber, sino como una posibilidad de experimentar el pensamiento, también se ofrecía otra posibilidad de relación con la infancia, a la vez que nos permitía a quienes trabajamos en la universidad salir un poco de allí y hacer cosas que se relacionaran de manera más directa con la vida, con la sociedad, lo cual, me resultó muy inspirador.

L. D. ¿Cómo cree usted que la filosofía para y con niños transforma el pensar de la escuela?

W. K. Es difícil esa pregunta, porque el pensar de la escuela se puede entender de diversas maneras, como si hubiera un pensar en la escuela, como si la escuela pensara o como si las personas que están en la escuela pensaran. Luego, es una pregunta con varias posibilidades, así, si es posible transformar a la escuela, lo que se piensa en la escuela o a las personas que están en la escuela, porque la escuela en sentido como institución, no está hecha para transformar, existe para reproducir una cierta lógica social. Entonces intentar transformarla o problematizarla, no es fácil, puede ser que una parte, una dimensión de la escuela, no vea con buenos ojos a la filosofía o no le dé la bienvenida. Por ello, considero que ese es el primer trabajo, pensar si es posible y si están dadas las condiciones, de lo cotnrario, tratar de generarlas para que se pueda intentar, al menos, transformar lo que se piensa en la escuela.

K. CH. ¿Cuáles son sus argumentos para justificar la filosofia en la educación de la infancia?

W. K. El principal argumento, creo, es lo que se hace en la escuela, es decir, para mí, la razón principal la dan los niños y niñas. Es como invitar a la gente a ir a la escuela, ver lo que pasa y escuchar a la infancia, o entonces, ejercitarlo en casa cuando se tiene niños cerca o niñas cerca.

L. D. ¿Cuál es su concepción acerca de la infancia o las infancias?

W. K. Es algo que trabajo siempre, que he ido cambiando y que trato de mantener abierto, es decir, que la pregunta por la infancia nunca se agote, que la infancia sea un enigma y algo que todo el tiempo nos está invitando a pensar y a evitar definirla, 
cerrarla, atraparla o apresarla. Es como si hubiera muchos intentos. Son muchas las ciencias que buscan conocer, dominar o saber qué es la infancia, yo trato de liberar a la infancia o generar una relación con la infancia en la que ella siempre esté abierta a poder ser de otra manera, me empeño en dar justicia a la infancia como un enigma, un misterio, algo que nunca sabremos, que tal vez, no sea interesante saber porque cuando lo sabemos es como limitar o condicionar nuestra relación con ella y entonces, pierde fuerza. Por el contrario, el eje de comprensión debe permitir que la infancia muestre toda su fuerza.

L. D. ¿Cómo la infancia transforma el devenir educativo?

W. K. La infancia es el propio devenir, como cuando uno está atento a la infancia y no quiere educarla, formarla o controlarla. Se relaciona con que la infancia lleva las riendas del devenir, de lo que sucede en la educación. Es decir, como si la infancia fuera la protagonista, la que nos orienta a cómo habitar el espacio educativo; da señales, inspira, da hasta una lengua, una manera de hablar, una manera de habitar el mundo, de pensar y de relacionarnos entre nosotros. De esta manera, la infancia es una inspiración para la educación.

K. CH. Entonces, según las concepciones que se crean en la escuela, ¿estas transforman el devenir educativo para la infancia?

W. K. Las concepciones sí y muchas veces estas condicionan o determinan, porque, en general, las condiciones están fundamentadas sobre saberes, así que, vamos a suponer que los niños de tal año a tal año están en ciertatal etapa y van a poder hacer tal cosa, entonces hay docentes que solo esperan eso, limitan la potencia de la infancia a lo que ellos piensan que la infancia puede ser o hacer, en función de su edad o de su condición. De manera que se trata también, un poco de liberarnos de lo que supuestamente sabemos de la infancia.

K. CH. Desde su experiencia con filosofía e infancia, ¿cómo se han transformado sus procesos de interacción con la infancia?

W. K. Mucho, siempre, todo el tiempo, por suerte. Porque de eso se trata, de mantener abierta nuestra relación con la infancia al enigma que es y la potencia que representa. Entonces, trato de estar siempre dispuesto para poder alimentar, apreciar y dejar atravesar mi práctica educativa por las señales de la infancia. De modo que, ojalá esté lo suficientemente atento para que mi práctica sea cada vez más infantil y cada vez más sensible a la infancia.

L. D. Según su criterio ¿cuál sería la manera de considerar la infancia en los entornos educativos?

W. K. Hay muchas maneras, pero yo le apuesto a una sensibilidad para la infancia, para estar atentos y no hablar por la infancia, porque existe el prejuicio que como la infancia supuestamente no tiene voz, entonces nosotros tenemos que hablar 
por ella. Tampoco quiero hablar por otros. Lo que quisiera es que los que nos relacionamos con la infancia seamos lo suficientemente abiertos para dejarnos atravesar por las señales de la propia infancia.

K. CH. Cuando se habla de una temporalidad de la infancia, se piensa en los niños marginados, ¿qué pasa con el tiempo aiónico en esta situación de marginalidad?

W. K. Es una cuestión de experiencia que está abierta. Está claro que hay muchas condiciones en que la infancia sufre, los niños tienen que trabajar desde muy pequeños o son explotados sexualmente, en este sentido, la infancia cronológica, la niñez, está maltratada de diversas maneras; cuando esto se observa en las clases sociales más bajas, el abuso social, político y económico, aumenta considerablemente. Pero tampoco cerraría la cuestión, digo que los niños de las clases sociales más bajas, tal vez porque están expuestos a dificultades mayores, están condicionados a explotar su ingenio de manera más aguda. Entonces, siempre trato de confiar en la potencia y las posibilidades de la infancia de encontrar su propio tiempo.

L. D. Teniendo en cuenta el amplio conocimiento en sus prácticas de filosofar con infancias no cronológicas y de aprendizaje mutuo, ¿cuáles experiencias comprenden para usted un modo de vida?

W. K. Yo no tengo tanto conocimiento de nada, pero sí he tenido algunas experiencias. Creo que la infancia de los adultos, así muy adultos, a veces sorprende, por ejemplo, en contextos de marginalidad, de exclusión, o de personas con muchas dificultades que tal vez, no han tenido un tiempo de infancia tan prolongado. Es sorprendente cómo se recupera o se recuerda una dimensión infantil con una fuerza extraordinaria, porque es como cuando la vida no ha dado mucha oportunidad de vivir la infancia y al presentarse esa oportunidad, no la queremos soltar o la queremos vivir lo más intensamente posible. Entonces a veces, cuando se está más cerca de la muerte se aproxima al inicio de la vida, es como un círculo donde el fin y el inicio se tocan, y las cosas que sentimos cuando nos aproximamos a la muerte, en cierto modo, nos aproximan a las que sentimos cuando nacemos a la vida. Como si hubiera algo de la experiencia del que está en el fin, que se parece mucho a la experiencia del comienzo y que acerca a las personas que están cerca de la muerte con las que están iniciando la vida.

K. CH. ¿Cuál cree que es el papel de la infancia en la búsqueda de la plenitud del ser? W. K. Creo que en ese sentido la infancia es una inspiración, como una fuente de alegría. Es como si la infancia, en cierto modo, fuera ese mismo estado, como si permitiese vivir más libremente y a medida que crecemos vamos condicionándonos, poniéndonos más obstáculos o más condiciones. Creo entonces, que la infancia para esa búsqueda es una condición importantísima.

L. D. Ha pasado bastante tiempo desde que decidió acoger la filosofía para y con 
niños como una forma de vida. Haciendo un paralelo ¿cuáles considera han sido las transformaciones de mayor relevancia en usted y por qué?

W. K. Creo que muchas, pero tal vez la de mayor relevancia tiene que ver con el ser niño. Creo tal vez, que la cosa más importante es que la filosofía me ha permitido recordar que soy niño, recordar mi infancia y ver mi infancia, no como algo pasado y que hay superar para ser adulto, por el contrario, como una posibilidad de ser más un adulto como quiero ser de lo que era.

K. CH. Para terminar, ¿qué sugerencias daría a aquellos que trabajan o se relacionan con la infancia?

W. K. Una que dice Paulo Freire y es bien significativa: No dejen morir al niño o la niña que fueron, no piensen que la infancia se refiere solo a ser educado, sino sobre todo, algo que nos ayude a educar, es una condición para educar, en ese sentido, si perdemos la infancia, si la dejamos morir o no la recordamos, es como perder una parte principal de nosotros sin la cual es muy difícil educar, porque el trabajo de educar tiene casi como condición recordar que somos infancia.

\section{Reflexión}

Los grupos de investigación AIÓN: tiempo de la infancia y GIFSE Filosofía Sociedad y Educación de la UPTC, han desarrollado desde hace varios años una experiencia pedagógica que relaciona filosofía e infancia, a partir de lo cual, se han construido pensamientos que contribuyen desde diversas perspectivas al programa original de filosofía para niños.

En este sentido, y como parte de las actividades de formación y divulgación académica de los grupos de investigación, se realizó la conferencia taller Experiencias filosóficas con la primera infancia, organizada en la UPTC seccional Tunja. Este espacio de diálogo formativo propició la interacción entre los participantes, en su mayoría docentes, egresadas y estudiantes de la Licenciatura en Educación Infantil de la misma universidad, para pensar de otro modo, concebir y valorar la pregunta como una posibilidad de movilizar el pensamiento y construir conocimientos.

De esta manera, la experiencia de preguntar-se y preguntar-nos anima la discusión sobre la construcción de tiempos y espacios para filosofar con niños y niñas, para situar la admiración, la pregunta, el diálogo y la voz como formas válidas y necesarias de relacionarse consigo mismo, con el otro y con el mundo. También, se hace necesario practicar y promover experiencias de pensamiento filosófico con personas de diversas edades, sensibles a la capacidad de asombro, y así entender la infancia como una forma de experiencia más allá de los años crono-lógicos.

\section{Referencia Bibliográfica}

Kohan, W. (2020, 5 de marzo). Experiencias filosóficas con la primera infancia. [Conferencia taller]. Tunja. Universidad Pedagógica y Tecnológica de Colombia. 